\title{
On the mating system of the cooperatively breeding saddle-backed tamarin (Saguinus fuscicollis)
}

\author{
John Terborgh ${ }^{1}$ and Ann Wilson Goldizen ${ }^{2}$ \\ 1 Biology Department, Princeton University, Princeton, New Jersey 08544, USA \\ ${ }^{2}$ Division of Biological Sciences, University of Michigan, Ann Arbor, Michigan 48109, USA
}

Received January 9, 1984 / Accepted October 16, 1984

\begin{abstract}
Summary. This paper reports on 5 years of observations of individually marked saddle-backed tamarins (Saguinus fuscicollis, Callitrichidae). Although callitrichids have long been presumed to have a monogamous social system, this study shows that the breeding structure of saddle-back tamarin groups is highly variable. Groups most commonly include two or more adult males and a single reproductive female, but occasionally contain only a single pair of adults, or less often, two reproductively active females and one or more males. Data on group compositions, group formations, intergroup movements and copulations show that the social and mating systems of this species are more flexible than those of any other non-human primate yet studied. Infants (usually twins) were cared for by all group members. There were two classes of helpers: young, nonreproductive individuals who helped to care for full or half siblings, and cooperatively polyandrous males who cared for infants whom they may have fathered. The observations suggest that non-reproductive helpers may benefit from their helping behavior through a combination of inclusive fitness gains, reciprocal altruism, and the value of gaining experience at parental care.
\end{abstract}

\section{Introduction}

Marmosets and tamarins (callitrichidae) are New World monkeys weighing 100 to 800 grams (Hershkovitz 1977). Callitrichids generally live in small territorial groups and feed on a mixed diet of fruit, small prey and plant exudates (Dawson 1978; Izawa 1978; Neyman 1978; Ramirez et al. 1978; Garber 1980; Rylands 1981; Terborgh 1983). Because of the small size of wild groups (groups may contain from two to ten individuals), the strong, long-term pair bonds noted in captivity, and the overt hostility shown by adults towards other adults of the same sex (Wolfe et al. 1975; Epple 1978), callitrichids have been thought to possess a monogamous social system (Eisenberg et al. 1972; Epple 1972; Kleiman 1977). To date, however, insufficient evidence has been obtained from field studies to affirm or reject this presumption.

Several monogamous primates have been well studies in the wild, and in each case the groups have contained only a single adult of each sex (titi monkeys (Callicebus moloch and C. torguatus): Mason 1966; Kinzey et al. 1977; Wright 1984; night monkeys (Aotus trivirgatus): Wright 1978, 1984; gibbons and siamangs (Hylobates lar and Sumphalangus syndactylus): Ellefson 1974; Chivers 1974). Although several callitrichid species have bred successfully in captivity as simple pairs, wild callitrichid groups normally contain more than two adults (Dawson 1978; Neyman 1978; Rylands 1981; Soini 1982; Soini, unpublished data), a fact that is at odds with the situation of all primates known to be monogamous.

Callitrichids are also unusual among primates because litters typically consist of twins, and because all group members participate in caring for the young. Captive studies have shown that adult males are the primary infant carriers (Epple 1975; Hoage 1978; Ingram 1978), and at least in goldenlion tamarins (Leontopithecus rosalia), that all group members share food with infants (Brown and Mack 1978).

In this paper we provide documentation of the social system of wild groups of saddle-backed tamarins (Saguinus fuscicollis), providing evidence on group compositions, founding of new groups, transfers of individuals between groups, mating 
and infant care. Although the remarkably varied circumstances of different groups preclude any facile categorization of the social system, the most frequently observed social configuration can be termed cooperative polyandry.

\section{Materials and methods}

Study site and study periods. Our study site is the Cocha Cashu Biological Station in the Manu National Park in the Department of Madre de Dios in southeastern Peru $\left(11^{\circ} 55^{\prime} \mathrm{S}\right.$, $77^{\circ} 18^{\prime} \mathrm{W}$, elevation approximately $400 \mathrm{~m}$ ). The vegetation is moist tropical forest (Terborgh 1983).

Observations on tamarins were made during the following periods: July-November 1979, August-November 1980, AprilSeptember 1981, June-August 1982 and June-August 1983.

Capturing and marking tamarins and assessing group compositions. In 1979 all individuals in four S. fuscicollis groups were captured and marked. Two additional groups were completely marked in 1980 and 1982, and a temporary group was marked in 1981. All but one of the groups were trapped at least once each year after the original captures, permitting regular weighing and measuring of individuals and marking of new group members. A total of fifty $S$. fuscicollis were marked over the 5 year period.

The tamarins were trapped in National Live Traps $(41 \times 14 \times 14 \mathrm{~cm})$ baited with ripe plantains. A young $S$. fuscicollis male was used as a decoy during trapping in 1979 and 1980. He was placed in a cage at the base of a large liane-draped tree within the territory of the target group. Set traps were arranged within a few meters of the decoy. After 1980, trapping was done without a decoy, as all the tamarins in the study area were by then familiar with plantains.

Trapped animals were anesthetized with Ketamine, weighed, measured, marked, and later released at the trap site after recovering. Each individual was marked with a numbered eartag, and those over $1 \frac{1}{2}$ years old were also fitted with a collar of stainless steel ballchian carrying three colored beads in a unique combination. Each year one individual in each group to be intensively followed was outfitted with a radio collar (AVM Instrument Company). Group compositions were determined by periodic censuses during each of the periods spent at the study site.

Behavioral and ecological data. Over $1,100 \mathrm{~h}$ of observations were made during 1979,1980 and 1981 on two of the study groups ( $\mathrm{H}$ and $\mathrm{SW})$. Observers followed the groups continuously from dawn to dusk, usually for seven to ten days consecutively. As the groups were completely habituated, the observer could follow the animals closely and record behavior in detail with the aid of binoculars. Radiotelemetry was used only to locate groups at the start of observation periods, or to relocate lost groups. Radiotelemetry was not used in routine following.

\section{Results}

\section{Group compositions}

The compositions of marked S. fuscicollis groups were generally stable, such that births and deaths predominated over intergroup transfers as the principle processes influencing group size and com-

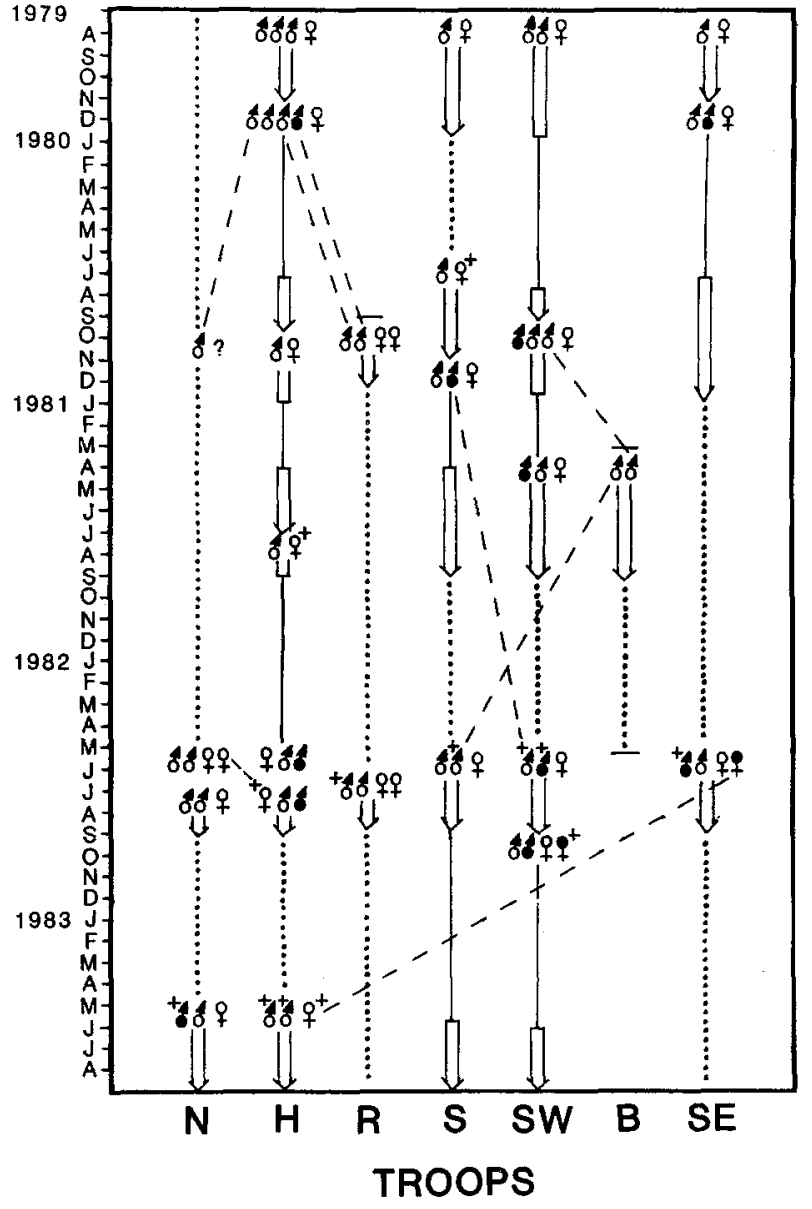

Fig. 1. Adult composition of seven saddle-backed troops over 5 years. Double lines represent compositions observed at least once a month; single lines represent groups whose adult compositions did not change over periods when observers were absent from the study site; dotted lines represent unknown compositions during prolonged intervals when observers were unable to check the groups, usually during the observers' absences from the site; dashed lines indicate transfers between groups. Symbols: of adult male; o adult female; + animals that had reached adulthood within their natal groups; $(+)$ indicates replacements of adult males and females; $\longrightarrow$ troop formation or extinction

position. Group sizes ranged from two (in temporary "bachelor" groups) or three (in the smallest reproductive groups) to ten. Over all periods when the exact memberships of the marked groups were known, they had the following adult compositions (by percent of group-months): one female and one male $(22 \%)$, one female and more than one male $(61 \%)$, more than one female and more than one male $(14 \%)$, and males only (3\%) (Fig. 1).

Cases of de novo group formations and migrations of marked animals provide important clues about the social system. Two new bisexual groups and two allmale groups formed in the study area between 1979 and 1983. (These changes are re- 
corded in Fig. 1, except for case 3). Case 1: In October 1980 a new group formed when two marked adult males from the " $\mathrm{H}$ " troop joined two unmarked nulliparous adult females that appeared one afternoon in the H group's territory. The foursome (later designated as " $R$ " troop) then emigrated to a new territory some $1 \frac{1}{2}$ kilometers away. Both females and at least one of the males were still together in August 1982. Case 2: Some time between September 1982 and May 1983 two adult males from outside the study area joined a nulliparous adult female, known since birth, and known to have still been in her natal group in August 1982. This group was established in the $\mathrm{H}$ territory by May 1983, replacing the previous $\mathrm{H}$ group which disappeared in the interim. Only one of the four prior members of the $\mathrm{H}$ group was found subsequently (see Case 3 ). Case 3 : Two adult males (both more than 6 years old) were observed living together in June 1983 around the boundary between two territories, both occupied by bisexual groups. Each of these males had been the older male in a different two-male bisexual group in 1982. They were not seen to interact with other groups, and it is not known what happened to them after June 1983. Case 4: In April 1981 two adult males joined and settled in a previously unoccupied territory (B group). They remained there for over 5 months, during which time they made at least three forays through three or more nearby territories. Each time they were back in their territory within 3 days.

Between October 1981 and June 1982, the S group, which has contained only one adult male, was joined by a second male (one of the $\mathrm{B}$ group males described under Case 4 above; the other B group male disappeared). The transferring male was at least $2^{1 / 2}$ years old and came originally from outside the study area. It is thus highly unlikely that the two associated $S$ group males were closely related. A year later, these two males were still in the $\mathrm{S}$ group, which had only one adult female during the interval.

\section{Observations on mating}

In four of five instances in which copulations were observed in groups having two adult males, both males copulated. (1) In one trio (two males, one female) observed continuously for ten days in April 1977, eleven copulations by identified males were witnessed. Five involved one male and six involved the other. The copulations of both males were scattered over the ten day period. Each male was observed to copulate in view of the other without inducing any sign of aggression. (2) During one of the episodes of troop formation ( $R$ troop), both males copulated with the two females. (3) After the $S$ troop had been joined by the second adult male (c.f. above), the new male copulated with the female. The other male had presumably fathered the female's offspring in 1980 and 1981, as he was then the group's only adult male. (4) In July 1982, the adult female of the $H$ troop disappeared and a new female joined the group. The group's two adult males copulated at least twice each with the new female during her first month in the group. One of the males was over five years old and had been in the group since at least 1979, while the second was a 2-year old born in the group. (5) In the fifth two-male group in which copulations were observed (SW group; 1983), only one male copulated. The other male was almost 4 years old, but was the son of the group's older adult female and the brother of the other.

In one, and possibly two groups, two females were known to copulate during the same season. (1) In the SW troop in 1983, the older of the two adult males copulated with both of the adult females (mother and daughter) during July, forming a temporary "consort relationship" with the younger female. (2) In 1982 the $N$ troop was found to contain two parous females and two litters of young less than 6 months apart in age, suggesting that both females had reproduced within the group. Shortly afterward one of these females moved to the neighboring $\mathrm{H}$ group, which has lost its female, leaving her young behind in the $\mathrm{N}$ troop.

Copulations have also been seen in groups containing one adult of each sex. Such groups are effectively monogamous, because copulations involving individuals from different groups have never been seen in many observations of intergroup encounters.

A form of "consort relationship", lasting for several days each time, was seen on two occasions. During these episodes, a male followed a female continuously, never allowing her to get more than a few meters away from him. Copulations were seen in both periods. These "consort relationships" appeared to be entirely maintained by the male, as the female's behavior was not in any way unusual. The circumstances in both cases were rather puzzling. In July 1982 a new female had just joined the $\mathrm{H}$ group (which had lost the previous resident female). Of the two males in the group, one was at least 5 years old and the other was the 2 year old son of the previous female. It was the younger male who "consorted" with the 

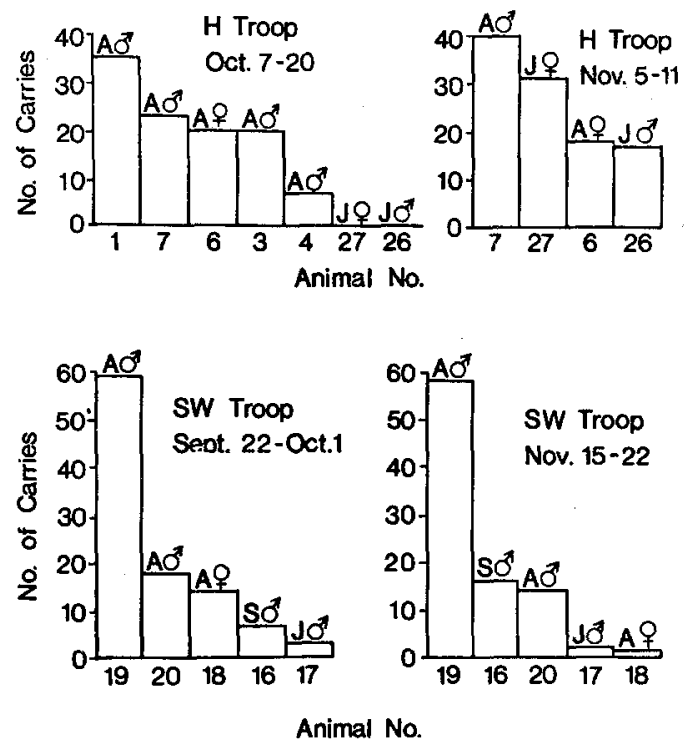

Fig. 2. Infant-carrying in two saddle-backed tamarin troops, 1980 . Instances of carrying were recorded at intervals $\geqq 15 \mathrm{~min}$, or when one or both infants switched to a new carrier. Between October 20 and November 5, three adult males (no. 1, 3 and 5) emigrated from the $H$ troop. The composition of the SW troop remained stable over the period

new female. In the SW group in 1983, the older of two males "consorted" with the younger of the two females (the daughter of the older female; the younger male was related to both females, c.f. no. 5 under Observations on Mating). In neither case did the groups' other adults display any aggression towards the "consorting" pairs.

All of the copulations described above occurred between April and October at times of year when conceptions might have resulted. The gestation period in this species is 150 days (Epple 1978). At Cocha Cashu there is a seasonal peak of births in the period September-November, but litters occasionally arrive as late as March. Unfortunately, exact dates of the births following observed copulations are not known, because observers are not continuously present at the study site.

\section{Observations on infant care}

Infants are carried in all group movements until they are $2-3$ months old. Often, one adult carries both infants together. Infant-carrying was recorded in 1979 and 1980 in two multi-male groups, and in each case, all adult males present contributed subsequently to infant-carrying (Fig. 2). Over the same period, a yearling male present in the SW group did very little carrying relative to the three older male members of the group (lower part, Fig. 2). It thus appears that older group members normally carry the infants, but that younger individuals may contribute substantially in small groups lacking supernumerary adults.

Each member of the SW troop in 1980 was observed to allow the 3-month old infants to take fruits and large katydids from its hands. The infants did not appear to be stealing these insects; rather, the older individual often appeared to hold the insect in a way that facilitated the infant's access to it.

\section{Discussion}

This paper describes three new findings on wild saddle-backed tamarins: (1) groups often contain more than one sexually active male and/or female; (2) new groups are often constituted by more than two adults; in the cases observed, either two males and one female or two individuals of each sex; (3) infant care is shared by adult group members in multi-male groups. S. fuscicollis have been kept successfully in captivity in two-male one-female trios, and in such groups both males sometimes copulate with the female (Epple 1972). In the wild, this behavior appears to be routine. These observations suggest that the social and mating systems of the saddle-backed tamarin are more complex and flexible than previously thought.

Helping behavior (Skutch 1961), defined as the care of infants by individuals other than the parents, has been reported for over 150 bird species (renewed by Brown 1978; Emlen 1978), and for over 30 mammal species, mostly carnivores (Rood 1978; Mochlman 1979; Malcolm and Marten 1982). The importance of helpers in callitrichids is probably related to the exceptional weight of the litters. Among callitrichids, twins are three to four times as common as single infants (Hampton and Hampton 1965), and the weights of litters of twins at birth range from 14-18\% of the mother's weight in Saguinus species, and up to about $25 \%$ of her weight in other callitrichid species (Kleiman 1977).

Two classes of helpers occur in the study population. The first consists of one- and two-year old individuals, and occasionally older animals who are not reproductively active and help to raise their full or half siblings. The second helper class consists of sexually active adult males who copulate with the female and then help to raise her young. An understanding of the helping behavior of these two classes of individuals need not be based on the same explanation.

Young pre-reproductive helpers may benefit from their helping behavior in any or all of the 
following ways: through inclusive fitness gains via kin selection (Hamilton 1964; West Eberhard 1975), reciprocal altruism (Trivers 1971; Axelrod and Hamilton 1981), or increased future reproductive success due to early experience at parental care (Gartlan 1969; Lancaster 1971). As long as the aid of these helpers does in fact increase their parents' reproductive success, the helpers would be increasing their own inclusive fitness. Even if the parents were capable of doing all of the infantcarrying by themselves, the helpers' aid might allow the parents to conserve energy, survive longer, and/or breed again sooner than would otherwise be possible. Thus, kin selection is plausibly a force in the evolution of the behavior of this helper class. That reciprocal altruism may occasionally be involved is suggested by two cases in which individuals rose to breeding status in their natal groups. One of these cases involved a female who replaced her mother as the breeding female of her group, and the other involved a male who mated with the female who replaced his mother. In both cases the individuals in question disappeared prior to the subsequent field season, so whether they would have been helped by their younger siblings remains unresolved. Experience at caring for infants has been shown to be very important for successful reproduction in callitrichids in the laboratory (Epple 1978; Hoage 1978). This may also be a contributory factor in the evolution of helping in S. fuscicollis.

The second class of helpers consists of polyandrous males. Cooperative polyandry is a rare form of cooperative breeding reported so far only in a few Asian human tribes (e.g. Goldstein 1971), and in several bird species; for example, the Tasmanian native hen (Tribonyx mortierii) (Maynard Smith and Ridpath 1972) and the Galapagos hawk (Buteo galapagoensis) (Faaborg et al. 1980). In the African hunting dog (Lycaon pictus) as well, more than one male has been reported to mate with a group's reproductive female and then to help raise her young (Malcolm and Marten 1982). For this paper, cooperatively polyandrous groups are defined as groups in which two or more males copulate with a single female during a single breeding season, and collaborate to raise her offspring. Presumably the paternity of the infants is not known to any of the individuals involved. Explanations for the occurrence of cooperative polyandry have been proposed by Maynard Smith and Ridpath (1972), Faaborg and Patterson (1981) and Stacey (1982).

Why might more than one male be needed to assure the reproductive success of a group? Al- though the data needed to provide a definitive answer to this question are not yet available, several circumstances suggest that extra males may contribute substantially to the rearing of offspring. The litter at birth constitutes nearly $20 \%$ of adult weight and by the time the young are independently locomoting this proportion increases to close to $50 \%$. The burden of the young imposes severe restrictions on the carrier, who travels in a conspicuously labored fashion in the cover of the understory and neither feeds nor insect forages. Meanwhile, the female, whose metabolism is greatly accelerated by the demands of lactation, devotes more time to feeding and insect foraging than other group members (unpublished results). Were the female to share the carrying with only one other group member, it is likely that the additional time and energetic costs would compromise her opportunity to feed, and thereby to supply milk to the offspring. The lone male carrier would also be under stress, as his need to feed would conflict directly with that of the female. With two males present (in the absence of younger helpers), one can carry and babysit while the other feeds and vice versa, leaving the female less hampered by these duties and free to feed ad libitum.

These circumstances can plausibly account for some additional observations. To date, the only single adult male/single adult female groups in the marked population to produce litters have been accompanied by pre-reproductive helpers. We have never definitely seen a male/female pair alone in the wild. Moreover, all of the new groups that have formed during the study have contained at least three adults. The implication is that by cooperating, two (or occasionally more) males can enhance their mutual reproductive success over what it would be were they to form monogamous pairs. Unfortunately, this is a proposition that is impossible to test, because, as already pointed out, simple pairs do not seem to occur in nature.

For selection to favor the cooperation of males in the rearing of young, one would imagine that both (or all) males must have some reasonable probability of paternity. This could be true only if all the males had access to the female at the time of ovulation, or if the males copulated at random in the absence of any clues to the state of the female's ovarian cycle. At present there is insufficient evidence to support either of these possibilities. The data from captive callitrichids is ambiguous. Kleiman (1978) found some behavioral correlates of the ovarian cycle in golden-lion tamarins (Leontopithecus rosalia rosalia), but Hearn (1978) and Brand and Martin (1983) found no behavior- 
ally or morphologically obvious signs of estrus, respectively, in common marmosets (Callithrix jacchus) and cotton-top tamarins (Saguinus oedipus). Both species were observed to copulate throughout the ovarian cycle, as our observations indicate for $S$. fuscicollis. The possibility thus cannot be excluded that some callitrichids may have a "concealed estrus", as has been suggested for humans (Alexander and Noonan 1979). In such a case, when two or more males have access to a female, paternity becomes a matter of probabilities. Just how such probabilities might be modified by occasional bouts of consorting is not yet clear. The two isolated episodes of consorting we have observed both took place under peculiar circumstances and are difficult to interpret (see above); normally males do not guard the female and copulations by any one are not impeded by the other(s).

Further results are needed to clarify the factors that determine whether particular tamarin groups have one or more than one reproductively active adult of each sex. It does not seem to be a matter of habitat or territory size, because groups occupying given territories have changed mating systems over time. The heretofore unreported occurrence of two reproducing females in a single group is a rare and probably unstable situation that adds further complexity to the overall picture. Although many questions about this intriguing social system remain to be answered, it is already clear at this point that past presumptions of simple monogamy in callitrichids will have to be revised.

Acknowledgements. We wish to thank B. Bell, R. Evans, C. Janson, C. McVay, B. Mitchell, D. Moscovits, N. Muckenhirn, P. Neyman, M. Reichman, G. Russell, P. Stern and C. Wise for assistance in the field. Permission to use the Cocha Cashu Biological Station was graciously extended by the General Directorate of Forestry and Fauna of the Peruvian Ministry of Agriculture. This work was supported by NSF grants DEB7609831, DEB79-04750 and BNS79-15079, the National Geographic Society, two University of Michigan Block Grants, the Edwin Edwards Scholarship Fund of the University of Michigan, a Charles Toback Award from the T.C. Schneirla Research Fund, Grant no. 220 of the Joseph Henry Fund of the National Academy of Sciences, and a Grant-in-Aid of Research from Sigma-Xi, The Scientific Research Society. Finally, we wish to thank two anonymous reviewers for their throughtful and constructive comments on an earlier draft of the manuscript.

\section{References}

Alexander RD, Noonan KM (1979) Concealment of ovulation, parental care, and human social evolution. In: Chagnon NA, Irons W (eds) Evolutionary biology and human social behavior: an anthropological perspective. Duxbury, North Scituate, Mass, pp 436-453

Axelrod R., Hamilton WD (1981) The evolution of cooperation. Science 211:1390-1396
Brand HM, Martin RD (1983) The relationship between female urinary estrogen excretion and mating behavior in cottontopped tamarins, Saguinus oedipus oedipus. Int J Primatol 4:275-290

Brown JL (1978) Avian communal breeding systems. Annu Rev Ecol Syst 9:123-155

Brown K, Mack DS (1978) Food sharing among captive Leontopithecus rosalia. Folia Primatol $29: 268-290$

Chivers DJ (1974) The siamang in Malaya: A field study of a primate in tropical rain forest. In: Contributions to primatology, vol 4. Karger, Basel

Dawson GA (1978) Composition and stability of social groups of the tamarin, Saguinus oedipus geoffroyi in Panama: ecological and behavioral implications. In: Kleiman DG (ed) The biology and conservation of the Callitrichidae. Smithsonian, Washington, DC, pp 23-38

Eisenberg JF, Muckenhirn NA, Rudran R (1972) The relation between ecology and social structure in primates. Science $176: 863-874$

Ellefson JO (1974) A natural history of white-handed gibbons in the Malayan peninsula. In: Rumbaugh DM (ed) Gibbon and Siamang, vol 3. Karger, New York, pp 1-136

Emlen ST (1978) The evolution of cooperative breeding in birds. In: Krebs JR, Davies NB (eds) Behavioral ecology: an evolutionary approach. Sinauer, Sunderland, Mass, pp 245-281

Epple G (1972) Social behavior of laboratory groups of $S$. fuscicollis. In: Bridgewater PD (ed) Saving the lion marmoset. Proceedings of the WAPT Golden Lion Marmoset Conference. WAPT, Oglebay Park, Wheeling, WVa, pp 50-58

Epple G (1975) Parental behavior in Saguinus fuscicollis spp. (Callitrichidae). Folia Primatol 24:221-238

Epple G (1978) Reproductive and social behavior of marmosets with special reference to captive breeding. Primates Med 10:50-62

Faaborg J, Patterson CB (1981) The characteristics and occurrence of cooperative polyandry. Ibis $123: 477-484$

Faaborg J, DeVies T, Patterson CB, Griffin CR (1980) Preliminary observations on the occurrence and evolution of polyandry in the Galapagos hawk (Buteo galapagoensis). Auk 97:581-590

Garber PA (1980) Locomotor behavior and feeding ecology of the Panamanian tamarin (Saguinus oedipus). Int J Primatol 1:185-201

Gartlan S (1969) Sexual and maternal behavior of the vervet monkey (Cercopithecus aethiops). J Reprod Fertil (Suppl) 6:137-150

Goldstein MC (1971) Stratification, polyandry, and family structure in Central Tibet. Southwest J Anthropol 27:64-74

Hamilton WD (1964) The genetical evolution of social behavior. I, II. J Theor Biol 7:1-52

Hampton JK Jr, Hampton SH (1965) Marmosets (Hapiladae): Breeding seasons, twinning, and sex of offspring. Science 150:915-917

Hearn JP (1978) The encocrinology of reproduction in the common marmoset, Callithrix jacchus. In: Kleiman DG (ed) The biology and conservation of the Callitrichidae. Smithsonian, Washington, DC, pp 163-171

Hershkovitz P (1977) Living new world monkeys (Platyrrhini), vol 1. University of Chicago Press, Chicago, Ill

Hoage RJ (1978) Parental care in Leontopithecus rosalia rosalia: Sex and age differences in carrying behavior and the role of prior experience. In: Kleiman DG (ed) The biology and conservation of the Callitrichidae. Smithsonian, Washington, DC, pp 293-305

Ingram JC (1978) Parent-infant interactions in the common marmoset (Callithrix jacchus). In: Kleiman DG (ed) The 
biology and conservation of the Callitrichidae. Smithsonian, Washington, DC, pp 281-291

Izawa K (1978) A field study of the ecology and behavior of the blackmantled tamarin (Saguinus nigrocollis). Primates 19:241-274

Kinzey WG, Rosenberger AL, Heisler PS, Prowse DL, Trilling JS (1977) A preliminary field investigation of the yellowhanded titi monkey, Callicebus torquatus torquatus, in northern Peru. Primates 18:159-181

Kleiman DG (1977) Monogamy in mammals. Q Rev Biol $52: 39-69$

Kleiman DG (1978) Characteristics of reproduction and sociosexual interactions in pairs of lion tamarins (Leontopithecus rosalia) during the reproductive cycle. In: Kleiman DG (ed) The biology and conservation of the Callitrichidae. Smithsonian, Washington, DC, pp 181-190

Lancaster JB (1971) Play mothering: The relationships between juvenile females and young infants among free-ranging vervet monkeys (Cercopithecus aethiops). Folia Primatol 15:161-182

Malcolm JR, Marten K (1982) Natural selection and the communal rearing of pups in African wild dogs (Lycaon pictus). Behav Ecol Sociobiol 10:1-13

Mason WA (1966) Social organization of the South American monkey, Callicebus moloch: A preliminary report. Tulane Stud Zool Bot 13:23-28

Maynard Smith J, Ridpath MG (1972) Wife sharing in the Tasmanian native hen, Tribonyx mortieri: A case of kin selection? Am Nat 106:447-452

Moehlman PD (1979) Jackal helpers and pup survival. Nature $277: 382-383$

Neyman PF (1978) Aspects of the ecology and social organization of freeranging cotton-top tamarins (Saguinus oedipus) and the conservation status of the species. In: Kleiman DG (ed) The biology and conservation of the Callitrichidae. Smithsonian, Washington, DC

Ramirez MF, Freese CH, Revilla J (1978) Feeding ecology of the pygmy marmoset, Cebuella pygmaea, in northeastern Peru. In: Kleiman DG (ed) The biology and conservation of the Callitrichidae. Smithsonian, Washington, DC, pp 91 104

Rood JP (1978) Dwarf mongoose helpers at the den. Z Tierpsychol $48: 277-287$

Rylands AB (1981) Preliminary field observations on the marmoset, Callithrix humeralifer intermedius (Hershkovitz, 1977) at Dardanelos, Rio Aripuana, Mato Grosso. Primates 22:46-59

Skutch AF (1961) Helpers among birds. Condor 63:198-226

Soini P (1982) Ecology and population dynamics of the pygmy marmoset, Cebuella pygmaea. Folia Primatol 39:1-21

Stacey PB (1982) Female promiscuity and male reproductive success in social birds and mammals. Am Nat 120:51-64

Terborgh J (1983) Five new world primates. Princeton University Press, Princeton, NJ

Trivers RL (1971) The evolution of reciprocal altruism. Q Rev Biol 46:35-57

West-Eberhard MJ (1975) The evolution of social behavior by kin selection. Q Rev Biol 50:1-33

Wolfe LG, Deinhardt F, Ogden JD, Adams JR, Fisher LE (1975) Reproduction of wild-caught and laboratory-born marmoset species used in biomedical research (Saguinus sp, Callithrix jacchus). Lab Anim Sci 25:802-813

Wright P (1978) Home range, activity pattern, and agonistic encounters of a group of night monkeys (Aotus trivirgatus) in Peru. Folia Primatol 29:43-55

Wright PC (1984) Biparental care in Aotus trivirgatus and Callicebus molach. In: Female primates: studies by women primatologists. Liss, New York, pp 59-75 